ЗДРАВООХРАНЕНИЕ И ПРОФИЛАКТИЧЕСКАЯ МЕДИЦИНА

\title{
PUBLIC HEALTH AND PREVENTIVE MEDICINE
}

\author{
DOI: 10.12731/2658-6649-2020-12-3-39-54
}

УДК 616.24-002-08:615.281.9

\section{СТАРТОВАЯ АНТИБАКТЕРИАЛЬНАЯ ТЕРАПИЯ ВНЕБОЛЬНИЧНОЙ ПНЕВМОНИИ В УСЛОВИЯХ РЕАЛЬНОЙ КЛИНИЧЕСКОЙ ПРАКТИКИ}

\author{
Шабалина Д.О., Цибульская Н.Ю., \\ Козлов Е.В., Харьков Е.И.
}

Цель. Провести анализ реальной клинической практики назначения стартовой антибактериальной терапии больным с внебольничной пневмонией в пульмонологическом отделении многопрофильного стационара и оценить ее соответствие клиническим рекомендациям.

Материалы и методы. В ретроспективном исследовании был произведен анализ 100 историй болезней и листов врачебных назначений пациентов, госпитализированных в пульмонологическое отделение Больниць скорой медицинской помощи с диагнозом «внебольничная пневмония» 6 период с июля по декабрь 2019 года. В исследование включались все паииенты с внебольничной пневмонией, которая диагностировалась на основании совокупности методов исследования: анамнестических данных, клинико-физикальных и лабораторно-рентгенологических.

Результаты. Гендерное распределение, включенных в исследование паииентов, составило 43 женщины и 57 мужчин. Медиана возраста у мужчин составила 48 лет, а у женщин - 55. Тяжелое течение внебольничной пневмонии наблюдалось у $30 \%$ больных. Антибактериальную терапию на амбулаторном этапе получали 1/5 больныхх. Стартовая антимикробная 
терапия в стационаре в 93\% случаев была комбинированной. Среди комбинаций преобладали левофлоксаџин + цеертриаксон (50\%), ампициллин/ сульбактам + левофлоксацин (31\%) и левофлоксацин + амоксициллин/ клавуланат (19\%). Комбинированная антимикробная терапия применялась в $65 \%$ случаев.

Заключение. Стартовая антибактериальная терапия внебольничной пневмонии в условиях пульмонологическом отделении многопрофильного стационара была назначена в соответствии с клиническими рекомендаичияи, что позволяет снизить число осложнений и уменьшить летальность от внебольничной пневмонии.

Ключевые слова: внебольничная пневмония; антибактериальная терапия; анализ реальной клинической практики; стационарное лечение внебольничной пневмонии.

\title{
STARTING ANTIBIOTIC THERAPY OF COMMUNITY-ACQUIRED PNEUMONIA IN REAL CLINICAL PRACTICE
}

\author{
Shabalina D.O., Tsibul'skaya N.Y., \\ Kozlov E.V., Khar'kov E.I.
}

Background. To analyze the real clinical practice of appointment starting antibacterial therapy for patients with community-acquired pneumonia in the Department of Pulmonology of a multidisciplinary hospital and estimate its compliance with clinical recommendation.

Materials and methods. In a retrospective study, an analysis was made of 100 case histories and sheets of medical prescriptions for patients hospitalized in the pulmonology department of the Emergency Hospital with a diagnosis of community-acquired pneumonia from July to December 2019. The study included all patients with community-acquired pneumonia, which was diagnosed on the basis of a set of research methods: medical history, clinical-physical and laboratory-radiological data..

Results. The gender distributions of the patients included in the study was 43 women and 57 men. The median age in men was 48 years old, and in women55. Severe community-acquired pneumonia was observed in $30 \%$ of patients. 1/5 patients received antibacterial therapy on an outpatient basis. Starting antibiotic therapy in the hospital in 93\% was combined. Among combinations levofloxacin + ceftriaxone (50\%), ampicillin/sulbactam + levofloxacin (31\%) 
and levofloxacin + amoxicillin/clavulanate (19\%) prevailed. Combined antibiotic therapy was used in $65 \%$.

Conclusion. Initial antibiotic therapy for community-acquired pneumonia in the pulmonary department of a multidisciplinary hospital was prescribed in accordance with clinical recommendations, which reduces the number of complications and mortality from community-acquired pneumonia.

Keywords: community-acquired pneumonia; antibiotic therapy; analysis of real clinical practice; hospital treatment.

Согласно официальной статистике государственного доклада «О состоянии санитарно-эпидемиологического благополучия населения в 2018 году», заболеваемость внебольничной пневмонией составила 491,67 на 100 тыс. населения, что на 16\% выше заболеваемости в 2017 году [1]. Также на 2018 год сохраняется тенденция к увеличению заболеваемости пневмонии вирусной и бактериальной этиологии, включая пневмококковую. В нашей стране в 2018 году смертность от внебольничной пневмонии среди лиц в возрасте 18 лет и старше в среднем по стране составила 4,25 на 100 тыс. населения, причем наиболее высокая смертность регистрируется среди мужчин трудоспособного возраста [1]. О важности проблемы также свидетельствует тот факт, что по данным экспертов ВОЗ, на 2016 год число смертей от респираторных инфекций нижних дыхательных путей находится на 4 месте, уступая ишемической болезни сердца, инсульту и хронической обструктивной болезни легких [2].

Клинические и национальные рекомендации, составленные ведущими клиницистами на основе современной доказательной базы, являются основными и наиболее достоверными источниками информации для врачей и других медицинских специалистов по вопросам диагностики и лечения различных заболеваний, в том числе и внебольничной пневмонии [3]. Включение и распространение в реальной практике таких рекомендаций способствует уменьшению сроков пребывания пациентов в стационаpe, снижению смертности от различных осложнений и затрат на лечение. Однако для реализации этих целей необходима приверженность врачей к клиническим рекомендациям и строгий контроль качества оказания медицинской помощи $[3,4]$.

Анализ реальной клинической практики, как известно, позволяет определить направления в улучшении оказания медицинской помощи больным [5]. Для оценивания качества оказания помощи при внебольничной пневмонии, в последнее время используют такие индикаторы, как адекватный 
выбор стартовой антибактериальной терапии, использование ступенчатой терапии и соответствие стартового режима клиническим и национальным рекомендациям. Данные критерии оценки являются наиболее хорошо изученными при лечении внебольничной пневмонии [5-8].

Цель нашей работы - провести анализ клинической практики назначения стартовой терапии системных антимикробных препаратов больным внебольничной пневмонией в пульмонологическом отделении многопрофильного стационара.

\section{Материалы и методы}

В ретроспективном исследовании объектом для изучения являлись истории болезни и листы врачебных назначений пациентов, госпитализированных в пульмонологическое отделение Больницы скорой медицинской помощи с диагнозом «внебольничная пневмония» в период с июля по декабрь 2019 года. В исследование включались все пациенты с внебольничной пневмонией, которая диагностировалась на основании совокупности методов исследования: анамнестических данных, клинико-физикальных и лабораторно-рентгенологических. Критерий исключения: наличие онкологической патологии со стороны бронхо-легочной системы, туберкулез легких, идиопатический фиброзирующий альвеолит, ВИЧ-инфекции, тяжелых обострений фоновых заболеваний со стороны легких (хроническая обструктивная болезнь легких, бронхиальная астма), декомпенсированной сердечно-сосудистой патологии, что требовало проведение комплексной многокомпонентной терапии, включающей препараты различных фармакологических групп, обладающие возможным синергидным свойством, а также пациенты с индивидуальной непереносимостью антибактериальных препаратов включенные в список клинических рекомендаций по лечению внебольничной пневмонии.

Статистический анализ полученных данных осуществлялся в пакете прикладных программ STATISTICA 7.0. количественные признаки, отличающиеся от нормального распределения, описывались в виде медианы (Me), 25\% и 75\% процентилей [C25; С 75]; качественные признаки - в виде долей (в процентах) и абсолютных числах.

\section{Результаты и обсуждение}

Было проанализировано 100 историй болезней и листов врачебных назначений больных с внебольничной пневмонией. Гендерное распределение, включенных в исследование пациентов, составило 43 женщины и 57 
мужчин. Медиана возраста у мужчин составила 48 [35; 63] лет, а у женщин $-55[32 ; 71]$.

Наибольшее число случаев внебольничной пневмонии было выявлено в возрасте от 31 года до 40 лет и составило 21 случай из 100. После следует возрастная группа от 61 до 70 лет, в которой обнаружено 16 случаев, и группа от 51 до 60 лет - 15 случаев внебольничной пневмонии (рис. 1).

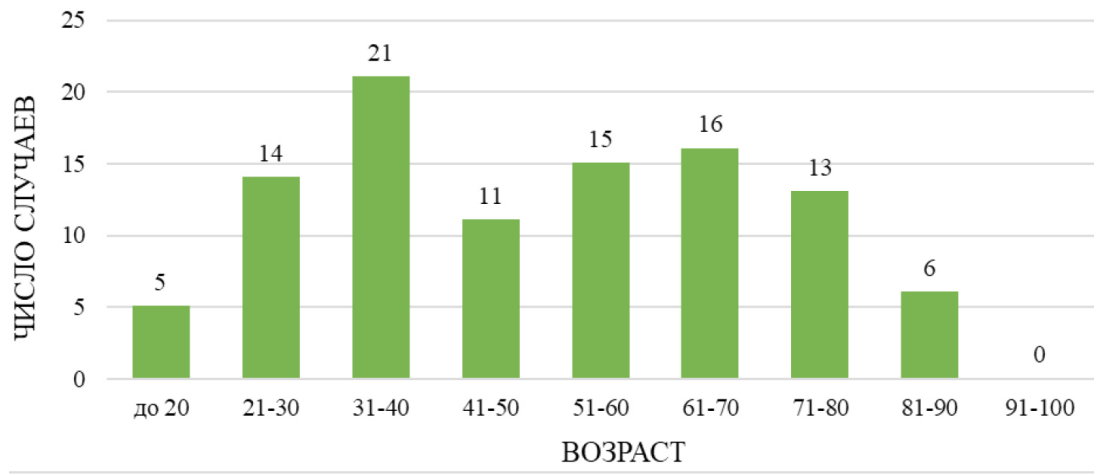

Рис. 1. Возрастная характеристика пациентов с внебольничной пневмонией

Тяжелая внебольничная пневмония наблюдалась у $30 \%$ больных, средней степени тяжести - у 70\%. Медиана возраста больных с тяжелой формой составила 63 [41; 74] года, а при средней степени тяжести 41 [32; 63]. При тяжелой форме у 73\% (22) пациентов наблюдались следующие осложнения: осумкованный экссудативный плеврит в $32 \%$ (7) случаев, острая дыхательная недостаточность в 54\% (12), сепсис в 14\% (3) случаев и абсцесс легкого в $14 \%$ (3). При внебольничной пневмонии средней степени тяжести были выявлены такие осложнения, как осумкованный экссудативный плеврит, который был выявлен в $6 \%$ (4) случаев, и острая дыхательная недостаточность - 7\% (5) (рис. 2).

У 40\% госпитализированных больных была выявлена сопутствующая патология. Из них чаще всего, а именно в $32,5 \%$ (13) случаев наблюдался гепатит В, в 32,5\% (13) - хроническая обструктивная болезнь легких, в 25\% (10) случаев - бронхиальная астма (в обострении средней степени тяжести с умеренными обструктивными нарушениями согласно данным спирографии) и у $25 \%$ (10) пациентов - сахарный диабет 2 типа (не осложненный, протекающий с гипергликемией на фоне интоксикационного синдрома). Не декомпенсированные сердечно-сосудистые заболевания в виде 
комбинированной патологии ишемическая болезнь сердца (ИБС)+сердечная недостаточность $(\mathrm{CH})$ были выявлены в 15\% (6) случаев больных,

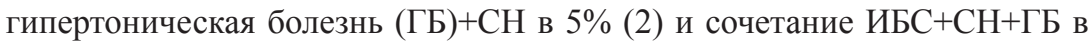
$5 \%$ (2) случаев.

$100 \%$

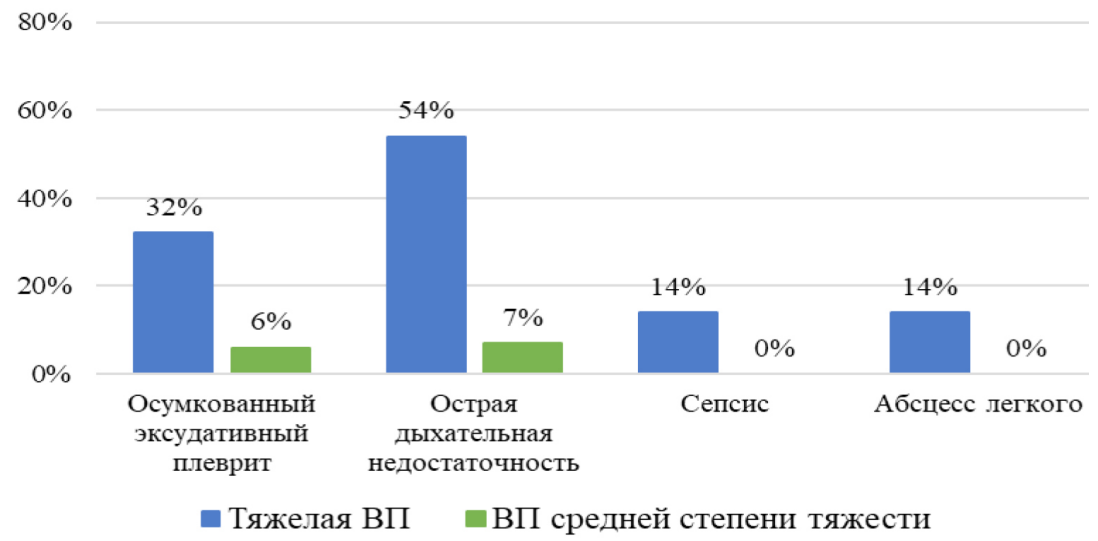

Рис. 2. Осложнения внебольничной пневмонии средней и тяжелой степени тяжести. (ВП - внебольничная пневмония)

На амбулаторном этапе около $21 \%$ больных получали антимикробные препараты. Лишь в $38 \%$ (8) случаев антибактериальная терапия была назначена врачом, в остальных случаях антибиотики принимались пациентами самостоятельно, без рецепта участкового врача-терапевта. Для лечения внебольничной пневмонии в амбулаторных условиях в 87,5\% (7) случаев были выбраны ингибиторозащищенные пенициллины, а именно: амоксициллин/клавуланат. Значительно реже использовали такой антибактериальный препарат, как азитромицин, относящийся к группе макролидов. Самостоятельно, без назначения врача, пациенты выбирали такие антибиотики, как амоксициллин (42\% (5)) и амоксициллин/клавуланат (58\% (7)).

При сопоставлении клинических рекомендаций с реальными результатами назначения антибактериальной терапии на догоспитальном этапе выяснилось, что во всех случаях терапия, назначенная участковым врачом, соответствовала рекомендациям.

Остается вопрос: почему при правильном назначении антимикробной терапии пациенты все равно обращались за помощью в стационар и были 
госпитализированы? При изучении амбулаторных карт данной категории пациентов был сделан следующий вывод: при оказании поликлинической помощи пациентам с подозрением на внебольничную пневмонию, антибактериальную терапию назначают сразу, а затем направляют на лабораторные и рентгенологические методы исследования. По результатам диагностики выставляют диагноз и определяют показания для госпитализации в стационар. В связи с коротким периодом приема антибиотиков нельзя достоверно оценить эффективность назначенного лечения.

При анализе листов врачебных назначений и историй болезней, которые оформлялись как дежурными врачами, так и штатными пульмонологами отделения, обнаружилось, что стартовая антибактериальная терапия в 93\% была комбинированной, то есть были использованы два и более антимикробных препарата. Среди наиболее востребованных комбинаций антибиотиков преобладали следующие: левофлоксацин + цефтриаксон $50 \%$ (47) случаев, ампициллин/сульбактам + левофлоксацин - 31\% (28), левофлоксацин + амоксициллин/клавуланат - 19\% (18).

При внебольничной пневмонии средней степени тяжести чаще всего использовали такие комбинации антимикробных препаратов, как левофлоксацин + цефтриаксон 56\% (39), левофлоксацин + ампициллин/сульбактам 21\% (15) и левофлоксацин + амоксициллин/клавуланат 13\% (9). При осложнении данной пневмонии острой дыхательной недостаточностью или плевритом препаратами выбора являлась комбинация таких антибиотиков, как левофлоксацин + цефтриаксон.

При тяжелой внебольничной пневмонии чаще всего использовали комбинации таких антибактериальных препаратов, как левофлоксацин + цефтриаксон - в 50\% (15) случаев и левофлоксацин + ампициллин/сульбактам - в 33\% (10). При тяжелой форме внебольничной пневмонии, осложненной сепсисом, острой дыхательной недостаточностью или абсцессом легкого, препаратами выбора являлась комбинация левофлоксацина + цефтриаксона. При таком осложнении тяжелой пневмонии, как экссудативный плеврит, в качестве комбинированной терапии в равной степени назначались как левофлоксацин + цефтриаксон, так и левофлоксацин + ампициллин/сульбактам.

В клинических рекомендациях 2018 года респираторные фторхинолоны являются альтернативными препаратами при лечении больных с внебольничной пневмонией [9-12]. Однако, в реальной клинической практике данный антибиотик использовался практически у каждого второго госпитализированного пациента. Это связано с тем, что, во-первых, боль- 
шинство пациентов имели коморбидную патологию и, таким образом, требовали более серьезную антибактериальную терапию, сочетающую в себе широкий спектр действия антибиотика, который способен воздействовать на все потенциальные возбудители пневмонии, требующей госпитализации, и благоприятные фармакокинетические параметры [9, 11-16]. Из них следует отметить такие параметры, как: длительный период полувыведения, что позволяет использовать препарат один раз в сутки; наличие пероральной и парентеральной лекарственной формы; биодоступность, приближающуюся к $100 \%$; приемлемый профиль безопасности и отсутствие серьезных нежелательных явлений со стороны сердца, почек, печени и центральной нервной системы; достижение высоких концентрации в бронхиальном секрете и легочной ткани и возможность взаимодействовать с другими лекарственными средствами без существенных негативных проявлений, так как респираторные фторхинолоны не метаболизируется ферментной системой цитохрома $\mathrm{P} 450$ [8, 10, 13-21].

Средний койко-день при внебольничной пневмонии средней степени тяжести составил $13[10 ; 19]$ дней, при тяжелой - 18,5 [15;28] дней.

При сопоставлении клинических рекомендаций с результатами, полученными нами в ходе исследования, было выявлено, что назначенные комбинации антимикробных препаратов соответствуют рекомендациям.

Ступенчатая терапия является общепризнанным стандартом лечения госпитализированных больных с внебольничной пневмонии, так как без потери конечной клинической эффективности позволяет сократить продолжительность пребывания больного в стационаре, а также позволяет уменьшить количество постинъекционных осложнений и существенно снизить затраты на лечение $[8,15,16,18]$. Ступенчатая антибактериальная терапия состоит из двух этапов применения антимикробных препаратов. Первый этап лечения начинается с внутривенного введения лекарственного средства, затем следует переход на пероральный прием того же препарата, либо препарата со схожим спектром активности и фармакодинамическими параметрами $[8,16,18,22,23]$. Такой переход может осуществляться только в случае снижении температуры тела, стабилизации гемодинамических показателей пациента, улучшении респираторных симптомов и признаков внебольничной пневмонии $[8,16,17,22,23]$. Последовательное применение двух лекарственных форм одного и того же антимикробного препарата (для парентерального введения и для перорального приема) является наиболее предпочтительным вариантом ступенчатой терапии и обеспечивает преемственность лечения [8]. 
В нашем исследовании ступенчатая терапия применялась в $65 \%$ случаев, что является довольно высоким показателем. В ходе лечения был переход с парентарального приема левофлоксацина на пероральный и переход с внутривенного введения ампициллина/сульбактама на пероральный прием амоксициллина/клавуланата. Переход с парентерального на пероральный режим терапии осуществлялся только после стабилизации гемодинамических показателей пациента, снижении температуры тела и улучшении клинических симптомов внебольничной пневмонии.

\section{Выводы}

1. Стартовая антибактериальная терапия в 93\% случаев была комбинированной: левофлоксацин + цефтриаксон - 50\% (47) случаев, ампициллин/сульбактам + левофлоксацин $-31 \%$ (28), левофлоксацин + амоксициллин/клавуланат - $19 \%$.

2. При тяжелой внебольничной пневмонии чаще всего использовали комбинации таких антимикробных препаратов, как левофлоксацин + цефтриаксон - в 50\% (15) случаев и левофлоксацин + ампициллин/ сульбактам - в 33\% (10), при абсцесцедировании легкого, препаратами выбора являлась комбинация левофлоксацина + цефтриаксона.

3. Ступенчатая терапия применялась в $65 \%$ случаев: переход с парентарального приема левофлоксацина на пероральный и переход с внутривенного введения ампициллина/сульбактама на пероральный прием амоксициллина/клавуланата. Переход с парентерального на пероральный режим терапии осуществлялся только после стабилизации гемодинамических показателей пациента, снижении температуры тела и улучшении клинических симптомов внебольничной пневмонии.

4. Антибиотики, использованные в качестве стартовой антибактериальной терапии госпитализированных больных, назначены в соответствии с клиническими рекомендациями.

Рациональное ведение больных с диагнозом «внебольничная пневмония», а также грамотное использование антибактериальной терапии как врачами-пульмонологами, так и другими врачами-специалистами позволяет сократить число осложнений и уменьшить летальность от данного заболевания.

\section{Список литературы}

1. О состоянии санитарно-эпидемиологического благополучия населения в Российской Федерации в 2018 году: Государственный доклад. М.: Феде- 
ральная служба по надзору в сфере защиты прав потребителей и благополучия человека, 2019. 254 с.

2. Global Health Estimates 2016: Deaths by Cause, Age, Sex, by Country and by Region, 2000-2016. Geneva, World Health Organization, 2018. URL: https:// www.who.int/ru/news-room/fact-sheets/detail/the-top-10-causes-of-death (дата обращения 31.01.2020).

3. Трифанова Н.М. Внебольничная пневмония: факторы риска неблагоприятного исхода и результаты внедрения территориального стандарта в Свердловской области: Дис. ... д-ра мед. наук. М., 2009. 145 с.

4. Синопальников А.И., Астафьев А.В., Стырт Е.А. Антибактериальная терапия внебольничной пневмонии в стационаре: реальная клиническая практика // Клиническая медицина. 2012. №12. С. 21-26.

5. Рачина С.А. Фармакоэпидемиологические, фармакоэкономические и фармакоэкономические подходы к ведению пациентов с внебольничной пневмонией в стационаре: Дис. ... д-ра мед. наук. Смоленск, 2010. 297 с.

6. Rhew D.C. Quality Indicators for the Management of Pneumonia in Vulnerable Elders // Annals of Internal Medicine, 2001, vol. 135, no. 8, pp. 736-743.

7. Restrepo, M.I., Anzueto, A. Severe Community-Acquired Pneumonia. Infectious Disease Clinics of North America, 2009, vol. 23, no. 3, pp. 503-520.

8. Rhew D.C., Goetz M.B., Shekelle P.G. Evaluating quality indicators for patients with community-acquired pneumonia // The Joint Commission Journal on Quality Improvement, 2001, vol. 27, no. 11, pp. 575-590.

9. Внебольничная пневмония у взрослых: практические рекомендации по диагностике, лечению и профилактике (пособие для врачей) / Чучалин А.Г., Синопальников А.И., Козлов Р.С., Тюрин И.Е., Рачина С.А. // Инфекционные болезни: Новости. Мнения. Обучение. 2013. №1. С. 81-113.

10. Фторхинолоны: вопросы эффективности и безопасности применения в пульмонологической практике / Лазарева Н.Б., Реброва Е.В., Рязанова А.Ю., Савинцева Д.Д. // Практическая пульмонология. 2019. №2. С. 58-68.

11. Стратегия и тактика рационального применения антимикробных средств в амбулаторной практике: Российские практические рекомендации / под ред. Яковлева С.В., Сидоренко С.В., Рафальского В.В., Спичак Т.В. М.: Издательство Престо, 2014. $121 \mathrm{c.}$

12. Синопальников А.И. Антибиотики и внебольничные инфекции нижних дыхательных путей. Кому? Какой? // Клиническая микробиология и антимикробная химиотерапия. 2019. №1. С. 27-38.

13. Chang S.-P., Lee H.-Z., Lai C.-C., Tang H.-J. The efficacy and safety of nemonoxacin compared with levofloxacin in the treatment of community- 
acquired pneumonia: a systemic review and meta-analysis of randomized controlled trials // Infection and Drug Resistance, 2019, vol. 12, pp. 433-438. doi:10.2147/idr.s193233

14. Zhao T., Chen L.-A., Wang P., Tian G., Ye F., Zhu H., He B., Zhang B., Shao C., Jie Z., Gao X., Wang D., Song W., Pan Z., Chen J., Zhang X., Gao Z., Chen P., Liu Y. A randomized, open, multicenter clinical study on the short course of intravenous infusion of $750 \mathrm{mg}$ of levofloxacin and the sequential standard course of intravenous infusion/oral administration of $500 \mathrm{mg}$ of levofloxacin for treatment of community-acquired pneumonia // Journal of Thoracic Disease, 2016, vol. 8, no. 9, pp. 2473-2484. doi:10.21037/jtd.2016.08.30

15. Cheng S.-L., Wu R.-G., Chuang, Y.-C., Perng, W.-C., Tsao, S.-M., Chang, Y.T., Chang L.-W., Hsu, M.-C. Integrated safety summary of phase II and III studies comparing oral nemonoxacin and levofloxacin in community-acquired pneumonia // Journal of Microbiology, Immunology and Infection, 2019, issue 52, pp. 743-751. doi:10.1016/j.jmii.2018.11.006

16. Клинические рекомендации по диагностике, лечению и профилактике тяжелой внебольничной пневмонии у взрослых / Чучалин А.Г., Синопальников А.И., Козлов Р.С., Авдеев С.Н., Тюрин И.Е., Руднов В.А., Рачина С.А., Фесенко О.В. // Клиническая микробиология и антимикробная химиотерапия. 2015. №2. С. 84-126.

17. Кунделеков А.Г., Нефёдов П.В., Колычева С.С. Лефокцин в медицинской практике // Современные проблемы науки и образования: электронный журнал, 2018. № 5. URL: http://www.science-education.ru/ru/article/ view?id=28040 (дата обращения: 04.02.2020).

18. Синопальников А.И. Левофлоксацин в ступенчатой терапии внебольничной пневмонии у взрослых // Практическая пульмонология. 2003. №2. C. 28-30.

19. Синопальников А.И. Место «Респираторных» фторхинолонов в лечении внебольничной пневмонии: фокус на высокодозный режим терапии левофлоксацином // Медицинский совет. 2017. №18. С. 65-69.

20. Синопальников А.И. Левофлоксацин: роль и место в лечении инфекций нижних дыхательных путей // Клиническая медицина. 2016. №11. С. 851-860.

21. Эффективность и безопасность немоноксацина в сравнении с левофлоксацином при внебольничной пневмонии: результаты многоцентрового, рандомизированного, двойного слепого, контролируемого исследования III фазы / Козлов Р.С., Дехнич А.В., Зайцев А.А., Нильк Р.Я., Самсонов М.Ю., Бережанский Б.В., Салазанов Д.А. // Клиническая микробиология и антимикробная химиотерапия. 2018. №4. С. 341-353. 
22. Антибактериальная терапия тяжелой внебольничной пневмонии у взрослых: обзор рекомендаций и клинические примеры / Рачина С.А., Козлов Р.С., Дехнич Н.Н., Бобылев А.А., Барашко О. Д. // Архивъ внутренней медицины. 2015. №3. С. 63-74.

23. Зайцев А.А. Внебольничная пневмония: "bene dignoscitur, bene curator" // Consilium Medicum. 2017. №3. C. 55-60.

\section{References}

1. O sostoyanii sanitarno-epidemiologicheskogo blagopoluchiya naseleniya $v$ Rossiyskoy Federatsii v 2018 godu: Gosudarstvennyy doklad [On the state of the sanitary-epidemiological well-being of the population in the Russian Federation in 2018: State report]. Moscow: Federal Service for Supervision of Consumer Rights Protection and Human Well-Being, 2019. 254 p.

2. Global Health Estimates 2016: Deaths by Cause, Age, Sex, by Country and by Region, 2000-2016. Geneva, World Health Organization, 2018. https://www. who.int/ru/news-room/fact-sheets/detail/the-top-10-causes-of-death (accessed January 31,2020 ).

3. Trifanova N.M. Vnebol'nichnaya pnevmoniya: faktory riska neblagopriyatnogo iskhoda i rezul taty vnedreniya territorial'nogo standarta $v$ Sverdlovskoj oblasti. Dokt, Diss. [Community-acquired pneumonia: risk factors for an adverse outcome and the results of applying the territorial standard in the Sverdlovsk region. Doct. Diss.]. Moscow, 2009. 145 c.

4. Sinopal'nikov A.I., Astaf'ev A.V., Styrt E.A. Antibakterial'naya terapiya vnebol'nichnoj pnevmonii v stacionare: real'naya klinicheskaya praktika [Antibacterial therapy of community-acquired pneumonia in a hospital: real clinical practice]. Klinicheskaya medicina [Clinical Medicine], 2012, issue 12, pp. 21-26.

5. Rachina S.A. Farmakoepidemiologicheskie, farmakoekonomicheskie i farmakoekonomicheskie podhody $k$ vedeniyu pacientov s vnebol'nichnoj pnevmoniej $v$ stacionare. Dokt, Diss. [Pharmacoepidemiological, pharmacoeconomic and pharmacoeconomic approaches to the management of patients with community-acquired pneumonia in a hospital. Doct. Diss.]. Smolensk, 2010. 297 p.

6. Rhew D.C. Quality Indicators for the Management of Pneumonia in Vulnerable Elders. Annals of Internal Medicine, 2001, vol. 135, no. 8, pp. 736-743.

7. Restrepo, M.I., Anzueto, A. Severe Community-Acquired Pneumonia. Infectious Disease Clinics of North America, 2009, vol. 23, no. 3, pp. 503-520.

8. Rhew D.C., Goetz M.B., Shekelle P.G. Evaluating quality indicators for patients with community-acquired pneumonia. The Joint Commission Journal on Quality Improvement, 2001, vol. 27, no. 11, pp. 575-590. 
9. Chuchalin A.G., Sinopal'nikov A.I., Kozlov R.S., Tyurin I.E., Rachina S.A. Vnebol'nichnaya pnevmoniya u vzroslyh: prakticheskie rekomendacii po diagnostike, lecheniyu i profilaktike (posobie dlya vrachej) [Community-acquired pneumonia in adults: practical recommendations for diagnosis, treatment and prevention (a manual for doctors)]. Infekcionnye bolezni: Novosti. Mneniya. Obuchenie. [Infectious Diseases: News. Opinions. Training.], 2012, issue 1, pp. 81-113.

10. Lazareva N.B., Rebrova E.V., Ryazanova A.YU., Savinceva D.D. Ftorhinolony: voprosy effektivnosti i bezopasnosti primeneniya v pul'monologicheskoj praktike [Fluoroquinolones: issues of efficacy and safety of use in pulmonological practice]. Prakticheskaya pul'monologiya [Practical Pulmonology], 2019, issue 2, pp. 58-68.

11. Yakovleva S.V., Sidorenko S.V., Rafal'skogo V.V., Spichak T.V. Strategiya i taktika racional'nogo primeneniya antimikrobny hredstv v ambulatornoj praktike: Rossijskie prakticheskie rekomendacii [Strategy and tactics for the rational use of antimicrobial agents in outpatient practice: Russian practical recommendations]. Moscow: Presto Publ., 2014. 121 p.

12. Sinopal'nikov A.I. Antibiotiki i vnebol'nichnye infekcii nizhnih dyhatel'nyh putej. Komu? Kakoj? [Antibiotics and community-acquired lower respiratory tract infections. To whom? which one?]. Klinicheskaya medicina [Clinical Medicine], 2019, issue 1, pp. 27-38.

13. Chang S.-P., Lee H.-Z., Lai C.-C., Tang H.-J. The efficacy and safety of nemonoxacin compared with levofloxacin in the treatment of community-acquired pneumonia: a systemic review and meta-analysis of randomized controlled trials. Infection and Drug Resistance, 2019, vol. 12, pp. 433-438. doi:10.2147/idr.s193233.

14. Zhao T., Chen L.-A., Wang P., Tian G., Ye F., Zhu H., He B., Zhang B., Shao C., Jie Z., Gao X., Wang D., Song W., Pan Z., Chen J., Zhang X., Gao Z., Chen P., Liu Y. A randomized, open, multicenter clinical study on the short course of intravenous infusion of $750 \mathrm{mg}$ of levofloxacin and the sequential standard course of intravenous infusion/oral administration of $500 \mathrm{mg}$ of levofloxacin for treatment of community-acquired pneumonia. Journal of Thoracic Disease, 2016, vol. 8, no. 9, pp. 2473-2484. doi:10.21037/jtd.2016.08.30.

15. Cheng S.-L., Wu R.-G., Chuang, Y.-C., Perng, W.-C., Tsao, S.-M., Chang, Y.-T., Chang L.-W., Hsu, M.-C. Integrated safety summary of phase II and III studies comparing oral nemonoxacin and levofloxacin in community-acquired pneumonia. Journal of Microbiology, Immunology and Infection, 2019, issue 52, pp. 743-751. doi:10.1016/j.jmii.2018.11.006.

16. Chuchalin A.G., Sinopal'nikov A.I., Kozlov R.S., Avdeev S.N., Tyurin I.E., Rudnov V.A., Rachina S.A., Fesenko O.V. Klinicheskie rekomendacii po diag- 
nostike, lecheniyu i profilaktike tyazheloj vnebol'nichnoj pnevmonii u vzroslyh [Clinical recommendations for the diagnosis, treatment and prevention of severe community-acquired pneumonia in adults]. Klinicheskaya mikrobiologiya $i$ antimikrobnaya himioterapiya [Clinical Microbiology and Antimicrobial Chemotherapy], 2015, issue 2, pp. 84-126.

17. Kundelekov A.G., Nefyodov P.V., Kolycheva S.S. Lefokcin v medicinskoj praktike. Sovremennye problemy nauki i obrazovaniya: elektronnyj zhurnal, 2018, issue 5. http://www.science-education.ru/ru/article/view?id=28040 (дата обращения: 04.02.2020).

18. Sinopal'nikov A.I. Levofloksacin v stupenchatoj terapii vnebol'nichnoj pnevmonii u vzroslyh [Levofloxacin in step therapy of community-acquired pneumonia in adults]. Prakticheskaya pul'monologiya [Practical Pulmonology], 2003, issue 2, pp. 28-30.

19. Sinopal'nikov A.I. Mesto «Respiratornyh» ftorhinolonov v lechenii vnebol'nichnoj pnevmonii: fokus na vysokodoznyj rezhim terapii levofloksacinom [The place of "Respiratory" fluoroquinolones in the treatment of community-acquired pneumonia: focus on high-dose levofloxacin therapy]. Medicinskij sovet [Medical Advice], 2017, issue 18, pp. 65-69.

20. Sinopal'nikov A.I. Levofloksacin: rol' i mesto v lechenii infekcij nizhnih dyhatel'nyh putej [Levofloxacin: role and place in the treatment of lower respiratory tract infections]. Klinicheskaya medicina [Clinical Medicine], 2012, issue 12, pp. 21-26.

21. Kozlov R.S., Dekhnich A.V., Zajcev A.A., Nil'k R.YA., Samsonov M.YU., Berezhanskij B.V., Salazanov D.A. Effektivnost' i bezopasnost' nemonoksacina $v$ sravnenii s levofloksacinom pri vnebol'nichnoj pnevmonii: rezul'taty mnogocentrovogo, randomizirovannogo, dvojnogo slepogo, kontroliruemogo issledovaniya III fazy [The efficacy and safety of nemonoxacin compared with levofloxacin in community-acquired pneumonia: results of a multicenter, randomized, double-blind, controlled phase III study]. Klinicheskaya mikrobiologiya $i$ antimikrobnaya himioterapiya [Clinical Microbiology and Antimicrobial Chemotherapy], 2018, issue 4, pp. 341-353.

22. Rachina S.A., Kozlov R.S., Dekhnich N.N., Bobylev A.A., Barashko O.D. Antibakterial'naya terapiya tyazheloj vnebol'nichnoj pnevmonii u vzroslyh: obzor rekomendacij i klinicheskie primery [Antibacterial therapy for severe community-acquired pneumonia in adults: a review of recommendations and clinical examples]. Arhiv" vnutrennej mediciny [Archive of Internal Medicine], 2015, issue 3, pp. 63-74.

23. Zajcev A.A. Vnebol'nichnaya pnevmoniya: "bene dignoscitur, bene curator" [Community-acquired pneumonia: "bene dignoscitur, bene curator"]. Consilium Medicum [Consilium Medicum], 2017, issue 3, pp. 55-60. 


\section{ДАННЫЕ ОБ АВТОРАХ}

Шабалина Дарья Олеговна, студентка 4 курса лечебного факультета Красноярский государственный медицинский университет имени профессора В.Ф. Войно-Ясенеикого

ул. Партизана Железняка, 1, г. Красноярск, 660022, Российская Федерачия dar.shabalina@gmail.com

Цибульская Наталья Юрьевна, доцент кафедры пропедевтики внутренних болезней и терапии, к.м.н.

Красноярский государственный медицинский университет имени профессора В.Ф. Войно-Ясенеикого

ул. Партизана Железняка, 1, г. Красноярск, 660022, Российская Федераиия

solna33@yandex.ru

Козлов Евгений Вячеславович, заведующий отделением пульмонологии, К.M.H.

Красноярская межрайонная клиническая больнича скорой медииинской помощи имени Н.С. Карповича ул. Курчатова, 17, г. Красноярск, 660062, Российская Федерация Kev-pulmonolog@mail.ru

Харьков Евгений Иванович, заведующий кафедрой пропедевтики внутренних болезней и терапии, д.м.н., профессор

Красноярский государственный медицинский университет имени профессора В.Ф. Войно-Ясенеикого

ул. Партизана Железняка, 1, г. Красноярск, 660022, Российская Федерачия

Harkov-50@mail.ru

\section{DATA ABOUT THE AUTHORS}

Shabalina Dar'ya Olegovna, 4th year student of the Faculty of Medicine Krasnoyarsk State Medical University named after Professor V.F. War-Yasenetsky

1, Partizan Zheleznyak Str., Krasnoyarsk, 660022, Russian Federation dar.shabalina@gmail.com 
Tsibul'skaya Natal'ya Yur'evna, Associate Professor, Department of Propaedeutics of Internal Diseases and Therapy, Cand. of Med. Sc., Asc. Prof. Krasnoyarsk State Medical University named after Professor V.F. War-Yasenetsky

1, Partizan Zheleznyak Str., Krasnoyarsk, 660022, Russian Federation solna33@yandex.ru

SPIN-code: $4238-8156$

ORCID: 0000-0003-0122-0884

Kozlov Evgeniy Vyacheslavovich, Head of the Department of Pulmonology, Cand. of Med. Sc.

Krasnoyarsk Interdistrict Clinical Emergency Hospital named after N.S. Karpovich

17, st. Kurchatova, Krasnoyarsk, 660062, Russian Federation

Kev-pulmonolog@mail.ru

Khar'kov Evgeniy Ivanovich, Head of the Department of Propaedeutics of Internal Diseases and Therapy, Dr. of Med. Sc., Prof.

Krasnoyarsk State Medical University named after Professor V.F. War-Yasenetsky

1, Partizan Zheleznyak Str., Krasnoyarsk, 660022, Russian Federation Harkov-50@mail.ru

ORCID: 0000-0002-8208-0926 